Tjalling C. Koopmans Research Institute

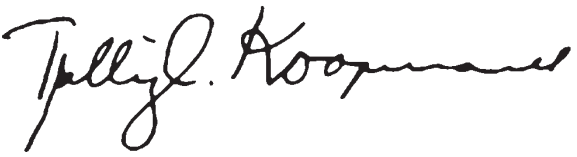

Discussion Paper Series nr: 09-30

\title{
At whose service? \\ Subsidizing services and the skill premium
}

Bas van Groezen

Lex M eijdam 


\section{Tjalling C. Koopmans Research Institute Utrecht School of Economics \\ Utrecht University}

Janskerkhof 12

3512 BL Utrecht

The Netherlands

telephone $\quad+31302539800$

fax +31302537373

website www.koopmansinstitute.uu.nl

The Tjalling C. Koopmans Institute is the research institute and research school of Utrecht School of Economics.

It was founded in 2003, and named after Professor Tjalling C. Koopmans, Dutch-born Nobel Prize laureate in economics of 1975.

In the discussion papers series the Koopmans Institute publishes results of ongoing research for early dissemination of research results, and to enhance discussion with colleagues.

Please send any comments and suggestions on the Koopmans institute, or this series to J.M.vanDort@uu.nl

ontwerp voorblad: WRIK Utrecht

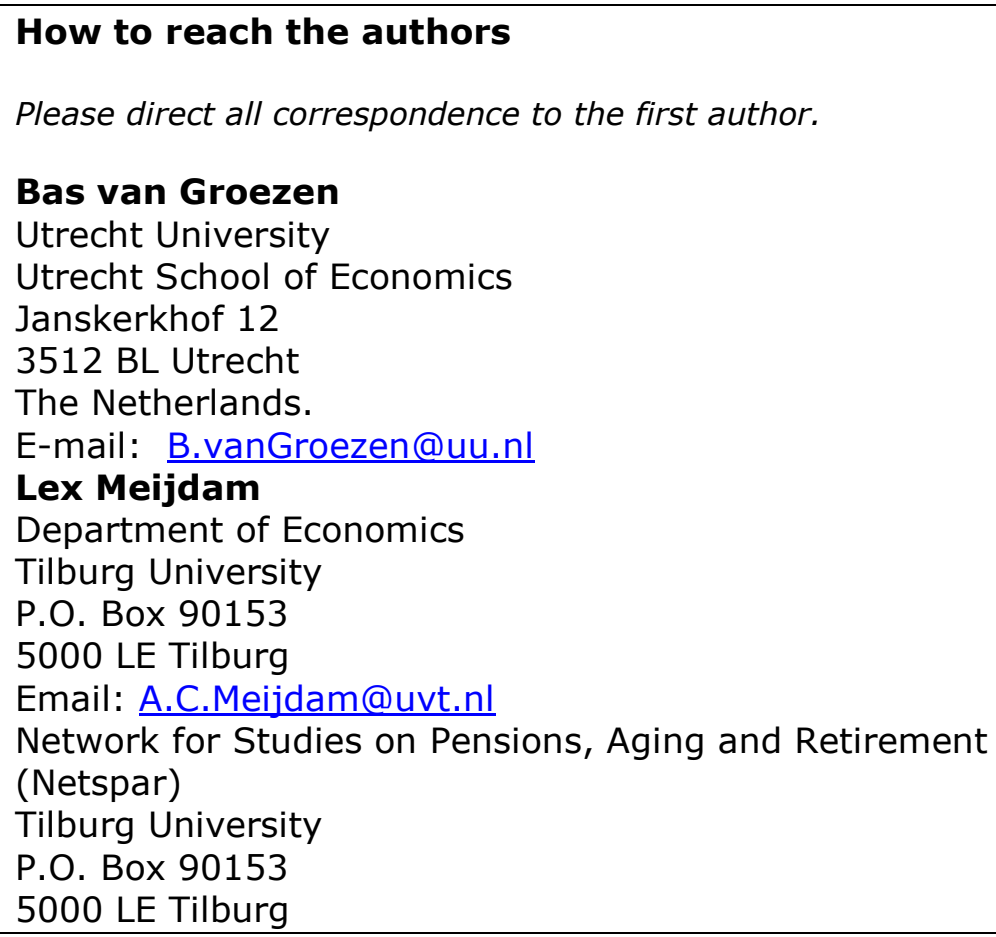


Utrecht School of Economics

Tjalling C. Koopmans Research Institute

Discussion Paper Series 09-30

\title{
At whose service? Subsidizing services and the skill premium
}

\author{
Bas van Groezen ${ }^{\mathrm{ab}}$ \\ Lex Meijdam ${ }^{\text {bc }}$ \\ aUtrecht School of Economics \\ Utrecht University \\ ${ }^{b}$ Network for Studies on Pensions, Aging and Retirement (Netspar) \\ Tilburg University \\ 'Department of Economics \\ Tilburg University
}

November 2009

\begin{abstract}
In this paper we investigate the effects of subsidizing low-skilled, labour-intensive services hired by high-skilled individuals in the presence of labour income taxation. Whether such a subsidy can be Pareto-improving depends crucially on the degree of substitutability of both types of labour in the non-service sector. In case of some substitutability, a service subsidy can benefit all and decrease inequality, but in case of complementarity, low-skilled individuals benefit and high-skilled individuals are worse off.
\end{abstract}

Keywords: household production, services, skill premium, subsidy, wage tax

JEL classification: D13, H24, H53, J13, J22, J24, O17 


\section{Introduction}

Stimulating labour market participation is high on the political agenda in many countries. This had led to a wide variety of measures, among which subsidized child care is one of the most striking examples: the direct and indirect subsidies for child care costs incurred by a dual-earner family range from $10 \%$ in the United Kingdom to more than $40 \%$ for Germany and The Netherlands (see Table 1). Another example is the application of a reduced VAT rate to certain labour-intensive services by member states of the EU, that intends to create jobs and reduce the 'black economy'. Comparing this with the standard VAT rate, this actually boils down to subsidizing these services relative to other goods by about 10\% (see Table 1). These policies have in common that they focus on favouring services that can quite easily be substituted by home-produced services. Because these services cannot be taxed, a tax on labour income not only distorts the consumption-leisure decision, but also the decision to hire market services, as it reduces the opportunity costs of providing home-produced services relative to the price of hired services. As was pointed out by Sandmo (1990), this leads to a distorted division of labour and consequently, substantial efficiency losses. Applying the theory of optimal taxation, Kleven et al. (2000) conclude that these market-produced services should be taxed at lower rates, which is also found by Kleven (2004) who argues that commodities which require little household time should be taxed at a lower rate than goods that are complements for leisure. Similar results were reported by Lindbeck (1982) and Bergstrom and Blomquist (1996), who focus on child care services and find that subsidizing these services increases labour supply to such an extent that tax rates do not have to rise, or can even decrease, especially if the market production of day care involves economies of scale, as in Lundholm and Ohlsson (1998). In a recent paper, Domeij and Klein (2009) apply a life-cycle model and show that especially if child-rearing is confined to a small part of the life cycle, tax deductibility of day care expenses is welfare improving because it allows distortions to be spread over different periods which reduces the total excess burden.

Although many have found supporting arguments for (tax-) subsidizing 
services, particularly child care, others doubt the efficiency enhancing effects. Rosen (1995) assumes a much smaller degree of substitutability between market and home produced services and concludes that there is a clear upper limit for subsidization of services to be desirable, beyond which the efficiency costs of higher taxes, needed to finance the subsidies, outweigh the benefits. Likewise, Mumford (2008) considers time spent on services, such as raising children, to be leisure time. With endogenous fertility, complementarity of children and leisure implies it is not optimal to subsidize child care. Blomquist et al. (2009) apply a model with different skill levels that are unobservable for the government, which redistributes income through a progressive tax system. Subsidizing services (that are required in order to work) by making these expenses tax deductible is found to be welfare decreasing as it induces high-skilled persons to work less and mimic low-skilled individuals.

Instead of concentrating on the degree of substitutability between homeprovided services and services hired on the market, in this paper, we focus on the substitutability of low and high-skilled labour in the productive sector and the general-equilibrium effects that a service subsidy brings about, both of which have so far received little attention. Providing services requires lowskilled labour, while both high and low-skilled labour is needed to produce commodities. This implies that the market price of services is determined by the wage of a low-skilled person. ${ }^{1}$ When deciding to hire services, a highskilled person compares this to his net wage; if the latter is lower due to a high wage tax, home-provision is more attractive for the individual. However, from a macroeconomic point of view, this is not efficient. The time spent by the high-skilled individual on home-provided services could have been used more productively by working. An obvious way to solve this is to decrease the tax. As we will show, this is only possible without loss of government revenues if both types of labour are very substitutable. Otherwise, subsidizing services is the second-best option to assure the same amount of revenues and grasp the benefits of more specialization. General-equilibrium effects determine to whom these benefits fall: on the one hand, high-skilled individuals benefit

\footnotetext{
${ }^{1}$ We abstract from a consumption tax or VAT. Adding this would not change the results. The subsidy on services can then also be interpreted as a tax subsidy in the form of a lower consumption tax or VAT.
} 
from receiving the subsidy and the opportunity to earn a higher income, but their increasing labour supply puts downward pressure on the return to highskilled labour. On the other hand, a higher demand for low-skilled labour in the services sector makes it more scarce in the productive sector, which has an upward effect on the wage of low-skilled labour and hence on the price of services. Again, the substitution elasticity of high and low-skilled labour is the determining factor. In case of rather high substitutability, a service subsidy can be both Pareto-improving and decrease inequality, but in case of complementarity, such a subsidy benefits low-skilled individuals while harming the high-skilled.

The rest of the paper is organized as follows. Section 2 describes the model, Section 3 focuses on market distortions for different degrees of substitutability of high and low-skilled labour, and analyses the effects of reducing the tax rate, providing service subsidies and making service expenses tax deductible. Section 4 concludes and discusses ideas for further research.

\section{The model}

\section{Consumers}

The economy is inhabited by an equal number of high-skilled and low-skilled individuals, each of whom is endowed with one unit of time. They derive utility from the consumption of commodities and leisure time, denoted by $c^{i}$ and $v^{i}$ respectively for skill type $i=s, u$ (high and low-skilled), given by the following CES-utility function:

$$
U^{i}=\left[\left(c^{i}\right)^{\alpha}+\left(v^{i}\right)^{\alpha}\right]^{1 / \alpha}
$$

with $\alpha<1$. Each unit of labour supplied earns a gross wage of $w^{i}$, which is taxed at a uniform rate $\tau$ in order to finance a minimum amount of necessary government expenditures equal to $E .^{2}$ Apart from supplying $L^{i}$ hours of labour, the individual needs a fixed amount of $\zeta$ services, which can be

\footnotetext{
${ }^{2}$ Allowing for a progressive tax system with different (marginal) tax rates for highskilled and low-skilled individuals would not qualitatively change our results. See also Section 3.3.
} 
thought of as child care, household chores (cleaning, gardening) and repairing work. These services are typically labour intensive and can either be provided by the individual himself or bought on the market for services. We assume one unit of service provision requires one unit of low-skilled labour, so the market price of a service equals the gross hourly wage of a low-skilled person, $w^{u}$. This implies that only the high-skilled, whose wages are higher, will potentially buy services. Let $x$ be the part of service consumption by the high-skilled that is bought on the market. This is determined by comparing the gross wage of low-skilled labour to the net wage of high-skilled labour (i.e., the opportunity cost of home provision of services). We can therefore distinguish three cases:

- $w^{u}<(1-\tau) w^{s} \quad \Rightarrow x=1$,

- $w^{u}=(1-\tau) w^{s} \quad \Rightarrow 0<x<1$,

- $w^{u}>(1-\tau) w^{s} \quad \Rightarrow x=0$.

In the first case, the market for services is completely utilized. In the second case, the market for services is partly utilized, while in the last case, this market does not exist at all. In the latter two cases, this implies that highskilled individuals use part of their time for home provision of services by giving up some hours of labour in the commodity sector, in which they are -by definition- more productive than low-skilled individuals.

The individual budget restriction for low-skilled individuals can then be written as

$$
c^{u}=(1-\tau) w^{u}\left(1-\zeta-v^{u}\right),
$$

and for high-skilled individuals as

$$
c^{s}=(1-\tau) w^{s}\left(1-(1-x) \zeta-v^{s}\right)-x \zeta w^{u}
$$

for high-skilled persons. Maximizing (1) subject to (2)-(3) gives the following labour supply functions,

$$
\begin{aligned}
L^{u} & =\frac{1-\zeta}{1+\left[(1-\tau) w^{u}\right]^{\alpha /(\alpha-1)}} \\
L^{s} & =\frac{1-(1-x) \zeta+x \zeta w^{u}\left[(1-\tau) w^{s}\right]^{(1-\alpha)}}{1+\left[(1-\tau) w^{s}\right]^{\alpha /(\alpha-1)}} .
\end{aligned}
$$




\section{Production}

The production of commodities is given by

$$
Y=\left[\left(\ell^{u}\right)^{\mu}+\left(\gamma \ell^{s}\right)^{\mu}\right]^{1 / \mu},
$$

with $\mu \leq 1$ and $\ell^{s}, \ell^{u}$ being the input of high and low-skilled labour, whose substitution elasticity is given by $1 /(1-\mu)$. Furthermore, $\gamma>1$, denoting the fact that the high-skilled are more productive in the commodity sector than low-skilled individuals. High-skilled only work in the commodity sector, i.e., $L^{s}=\ell^{s}$. Assuming perfect substitutability of low-skilled labour between the commodity sector and (home and market) service provision, ${ }^{3}$ we can write the supply of low-skilled labour to the commodity sector as

$$
\ell^{u}=L^{u}-x \zeta
$$

Profit maximization by firms implies that the wage of high and low-skilled labour is given by their marginal products:

$$
\begin{aligned}
w^{s} & =\gamma^{\mu}\left(\frac{Y}{l^{s}}\right)^{1-\mu}=\gamma^{\mu}\left(\frac{Y}{L^{s}}\right)^{1-\mu} \\
w^{u} & =\left(\frac{Y}{l^{u}}\right)^{1-\mu}=\left(\frac{Y}{L^{u}-x \zeta}\right)^{1-\mu} .
\end{aligned}
$$

Note that these wages depend on the hours of labour supplied to the commodity sector, which in their turn depend on the amount of services that the high-skilled buy on the market for services.

\section{Market distortions}

In this section, we show the effects of labour taxes and service subsidies for different degrees of substitutability between low and high-skilled labour in the production process. First, we focus on complete substitutability $(\mu=1)$, then on the intermediate case of a substitution elasticity equal to $1(\mu=0)$. Finally, the case of complementarity is analysed (for which we take $\mu=-10$ ).

\footnotetext{
${ }^{3}$ This is a common assumption, made by e.g. Lindbeck (1982), Sandmo (1990) and Kleven et al. (2000). An exception is Rosen (1995), whose conclusions hinge on the assumption of rather low substitutability between market and home produced day care.
} 


\subsection{Perfect substitutability}

If high and low-skilled labour are perfectly substitutable in the production of commodities $(\mu=1)$, (6) is a linear function and wages are exogenously given by $w^{s}=\gamma$ and $w^{u}=1$. This implies that the relative price of home services and market services does not change in response to changes in demand. Depending on the values of $\tau$ and $\gamma$, either the market for services is completely utilized $(x=1)^{4}$, or does not exist at all $(x=0)$. The latter is the case if $\tau>1-1 / \gamma \equiv \bar{\tau}$.

Note that according to (5), with a Cobb-Douglas utility function $(\alpha=0)$, high-skilled labour supply does not depend on the net wage as long as no services are purchased $(x=0)$, since the income and substitution effect of a change in the net wage cancel out. However, if the tax rate is below $\bar{\tau}, x$ has reached its maximum and does not change if $w$ is marginally changed. A lower value of the net wage then only causes a negative income effect leading to a higher labour supply. This implies that in that case, labour supply depends negatively on the net wage.

Furthermore, as shown in Figure 1.a, ${ }^{5}$ with linear production the Laffer curve has two peaks: the "normal" peak at $\tau^{m, 6}$ and an extra peak at $\tau=\bar{\tau}$, the tax rate above which the service market collapses. The optimal policy depends on the initial value of the labour income tax. Let $\tilde{\tau}<\tau^{m}$ be the rate at which tax revenues without utilization of the services market is equal

\footnotetext{
${ }^{4}$ It is possible that the labour supply of low-skilled individuals is smaller than the amount of services that the high-skilled want to buy. In that case, $x=L^{u} / \zeta<1$ instead of $x=1$.

${ }^{5}$ The parameter values for this figure are $\alpha=0.5$ and $\zeta=0.1$. Table 1 provides an indication of the fraction of time spent on services by individuals (which would actually be an estimate for $(1-x) \zeta$ ), that is on average between 21 and $35 \%$. However, because not all of these services can be replaced by hired services, and some are likely to be pleasant and therefore be part of leisure time in our model, we choose a 'safe' value of $10 \%$ for $\zeta$.

The value of $\gamma$ is set such that with a tax rate of $40 \%$, the resulting wage for high-skilled is $50 \%$ higher than the wage for low-skilled. Although Acemoglu (2003) reports a skill premium of $33 \%$ on average (see Table 1), the values found from comparing low-skilled and high-skilled wages as reported by CBS Statistics Netherlands and the US Bureau of Labor Statistics are much higher. We therefore take an intermediate value of $50 \%$.

${ }^{6}$ Defined as $\tau^{m} \equiv \arg \max _{\tau}\left\{\tau\left[\gamma L^{s}(\tau)+L^{u}(\tau)\right]\right\}$. Throughout the paper we will assume that tax rates are always below $\tau^{m}$.
} 
Figure 1: Laffer curves

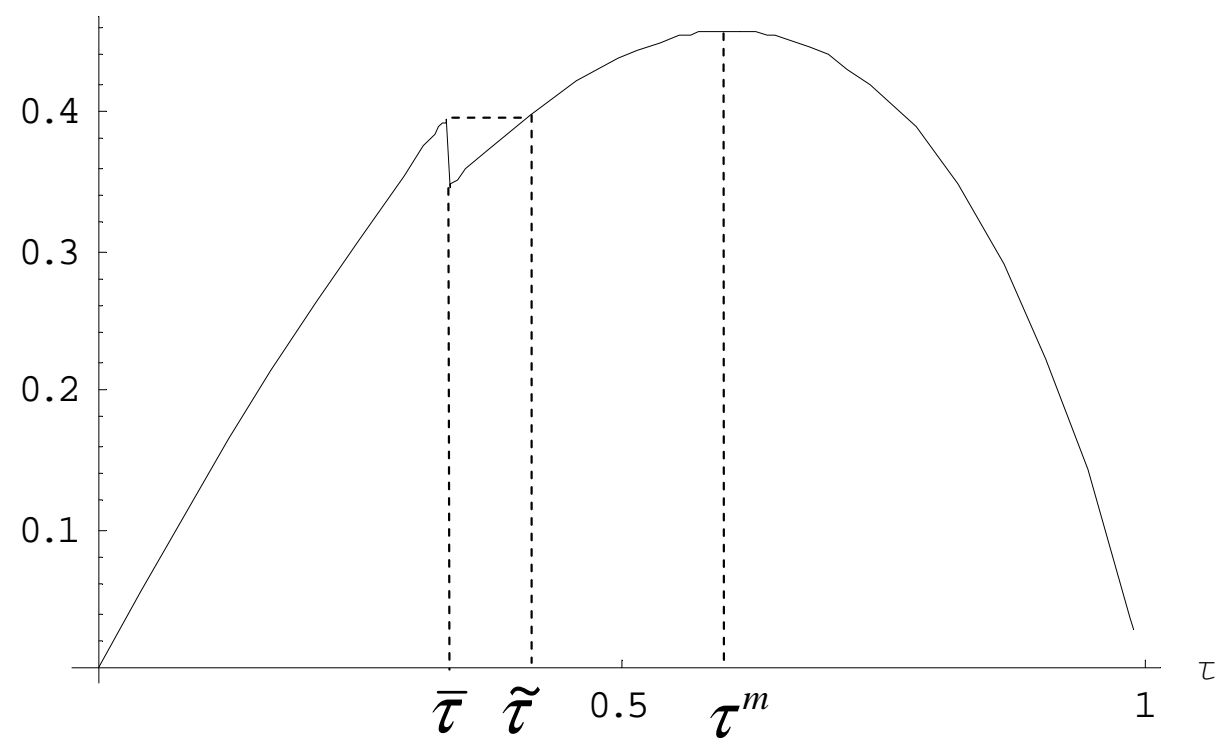

(a) Perfect substitutes $(\mu=1)$

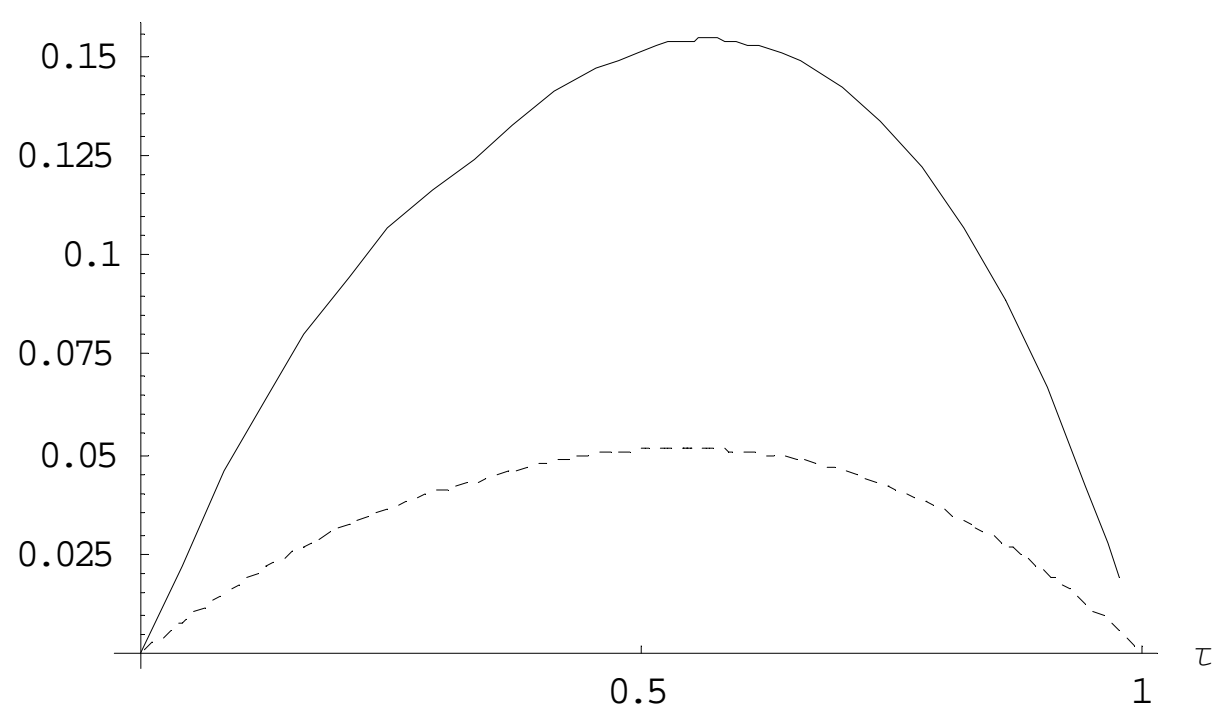

(b) Weak substitutes $(\mu=0) \quad \cdots-$ Complements $(\mu=-10)$ 
to the maximum amount of revenues in case all services are hired. ${ }^{7}$ Then, the following proposition holds.

Proposition 1. If $\mu=1$ and $\tau \in(\bar{\tau}, \tilde{\tau}]$, there exists a tax $\hat{\tau} \leq \bar{\tau}$ that raises the same amount of revenues $E$. The first-best policy is to decrease the tax rate to this lower tax $\hat{\tau}$.

In that case, the distortion of the services market is nullified: high-skilled individuals will increase their labour supply to the sector in which they are more productive, while low-skilled labour supply to the commodity sector will be reduced. Because of perfect substitutability, the latter effect is more than offset by the higher labour supply of high-skilled, and production increases. Because the tax rate is reduced for all and wages do not change, this is a Pareto-improving policy.

However, if $\tau \in\left(\tilde{\tau}, \tau^{m}\right]$, decreasing the wage tax to (slightly less than) $\bar{\tau}$ generates a lower amount of tax revenues than $E$, which we assume to be infeasible. As can be seen from Figure 1.b, this is especially so if production is non-linear, i.e., if low and high-skilled labour are to some extent complementary, which will subsequently be discussed.

\section{$3.2 \quad$ Non-linear production}

If labour of different skill types are not perfect substitutes, the wages are endogenous. Consequently, changes in tax rates that induce changes in labour supply will cause general-equilibrium effects that affect the tax base and tax revenues. This is clearly seen from comparing Figure 1.a and 1.b: if both types of labour are less than perfect substitutes, the Laffer curve has only one peak, and this peak occurs at a lower tax rate. Decreasing the tax rate to stimulate the market for services is then not possible without also decreasing tax revenues. Instead, it can be welfare-improving to introduce a subsidy $\theta$ for each hour of services that is hired. This will reduce the price of a service to $(1-\theta) w^{u}$ and change the fraction of services purchased on the market to $x^{\prime} \geq x$. The costs of subsidization are financed through a higher wage tax,

\footnotetext{
${ }^{7}$ Defined as $\tilde{\tau} \equiv\left\{\tau>\bar{\tau} \mid \lim _{\tau \uparrow \bar{\tau}} \tau\left[\gamma L^{s}(\tau)+L^{u}(\tau)\right]=\tilde{\tau}\left[\gamma L^{s}(\tilde{\tau})+L^{u}(\tilde{\tau})\right]\right\}$.
} 
though on the other hand, if effective, the subsidy will boost labour supply to $L^{s^{\prime}}$ and thus increase the tax base, creating room for a lower tax rate, which will subsequently also affect low-skilled labour supply. Let $\tau^{\prime}$ be the new tax rate that ensures budget neutrality. Then,

$$
\tau^{\prime}\left(L^{s^{\prime}} w^{s^{\prime}}+L^{u^{\prime}} w^{u^{\prime}}\right)=E+\theta x^{\prime} \zeta
$$

Furthermore, the following condition must hold,

$$
1-\left(1-\tau^{\prime}\right) w^{s^{\prime}} / w^{u^{\prime}}<\theta<\tau^{\prime}
$$

The left part of equation (11) ensures the subsidy is effective, the right part implies that the subsidy is lower than the tax on low-skilled labour and thus warrants that only the high-skilled will use the subsidy to purchase services. ${ }^{8}$ We will illustrate the effects of a service subsidy that satisfies conditions (10) and (11) for different values of the substitution elasticity, assuming an initial tax rate of $40 \% .^{9}$ With an initial skill premium of $50 \%\left(w^{s} / w^{u}=1.5\right)$, this implies that we start from a situation that no services are purchased on the market. For completeness, the effects of a service subsidy are also shown for the previous case of linear production (see Figures 2.a-f), together with the effects of a budgetary-neutral decrease of the tax rate. As discussed earlier, the latter option is better as it allows for a larger tax decrease, labour supply increase and utility gain.

\section{Unitary substitution elasticity}

With a unitary substitution elasticity (i.e., $\mu=0$ ), low and high-skilled labour are more complementary than before. The production function then boils down to

$$
Y=\left(\ell^{u}\right)^{\beta}\left(\gamma \ell^{s}\right)^{1-\beta}
$$

\footnotetext{
${ }^{8}$ This is to prevent a situation described by Rosen (1995) as " [...] a large fraction of women work [...] to take care of the children of other women who work [...] to take care for the parents of the women who are looking after their children" (p. 5).

${ }^{9}$ As can be seen from Table 1 , this is about the average in several OECD countries (including social security taxes and VAT) for an individual with an average income. A higher value would be applicable in case of the marginal wage tax.
} 
Figure $3 . \mathrm{a}^{10}$ shows that a subsidy of at least $10 \%$ is required to be effective. Only if $\theta=38 \%$, the market for services is completely utilized. As can be seen from Figure 3.b, the wage tax can be decreased as the subsidy increases because the tax base becomes larger: both labour supply of low and highskilled increases. Furthermore, the wage of the low-skilled increases because of the higher demand for their services and the fact that more high-skilled labour supply makes them more productive in the commodity sector due to some degree of complementarity; this, together with a lower tax rate, raises their utility. On the other hand, a higher subsidy has a negative effect on the wage earned by high-skilled individuals because of their increased labour supply. Figure 3.f shows the effects of a service subsidy on the utility of highskilled persons. For rather low levels of the subsidy, their utility increases because the combined effect of a lower tax and a lower net price of services outweighs the lower gross wage received. As the subsidy gets larger, the wage of low-skilled labour increases, so services become relatively more expensive, while the lower wage for high-skilled labour decreases further. Raising the subsidy to values higher than $22 \%$ makes the high-skilled worse off.

Concluding, with a moderate degree of substitutability between high and low-skilled labour in the productive sector, a service subsidy between 10 and $20 \%$ is Pareto-improving. Moreover, it will also reduce inequality between low and high-skilled individuals.

\section{Complementarity}

Figures 4.a-f show the effects of a services subsidy in case $\mu=-10$, so the substitution elasticity of low and high-skilled labour in the production process is very low. ${ }^{11}$ As can be seen in Figure 4.a, a subsidy of about $9 \%$ is at least required to instigate the market for services. However, at the maximum level of the subsidy, the market for services is still not completely utilized. Highskilled individuals will supply more labour, which, together with the higher demand for low-skilled labour, increases the wage of low-skilled workers. This effect is rather strong because of the high degree of complementarity and has a positive effect on low-skilled labour supply. Again, the growing tax base

\footnotetext{
${ }^{10}$ The values of $\beta$ and $\gamma$ are set such that again, $w^{s} / w^{u}=1.5$. The figures only show the cases when a subsidy is effective; for lower value of $\theta, x=0$.

${ }^{11}$ Lower values of $\mu$ produce qualitatively similar results.
} 
allows for a lower wage tax rate, despite the costs of providing the subsidy, as shown by Figure 4.b, but the decrease in the tax rate is less compared to the previous cases. Figures 4.e and 4.f reveal that also now, low-skilled persons always benefit from a higher subsidy. They experience the largest utility gain when $\theta$ is set at the highest possible level. On the other hand, high-skilled individuals do not benefit from a service subsidy at all. The small decrease in the tax rate and net price of services cannot compensate for the lower gross wage. So in this case, subsidizing services is not Pareto-improving, it merely reduces inequality.

\subsection{Tax-deductible service expenses}

Instead of providing direct subsidies for each unit of services purchased, the government can also make service expenses tax deductible (as in, e.g., Domeij and Klein (2009)). If $\eta$ denotes the degree of tax deductibility, the effective price of a service for a person with skill type $i$ becomes $\left(1-\eta \tau^{i}\right) w^{u}$. When both types of individuals face the same tax rate, as we assumed, this boils down to an implicit subsidy of $\eta \tau$, giving the same results as before. But if tax rates are different, e.g. because of a progressive tax system where $\tau^{s}>\tau^{u}$, tax deductibility allows for subsidies to be differentiated by skill type. With $\eta=100 \%$, high-skilled individuals will always decide to purchase all services; for lower values of $\eta$ the effects are the same as with a similar subsidy of $\eta \tau^{s}$. Low-skilled individuals on the other hand, will not purchase services if $\eta<100 \%$. The only difference with direct subsidies is therefore that in case of a lower marginal tax rate for low-skilled, the maximum subsidy that can be provided increases: with direct subsidization, the maximum rate is determined by the tax rate of low-skilled labour, $\left(\tau^{u}\right)^{12}$ while in case of tax deductibility, the maximum (implicit) subsidy equals the tax rate of the high-skilled $\left(\tau^{s}\right)$. Whether providing direct subsidies or indirect subsidies through the tax system is more suitable thus depends on whether a subsidy larger than $\tau^{u}$ is desirable.

\footnotetext{
${ }^{12}$ See the second part of equation (11).
} 


\section{Conclusion}

Concluding, we can say that the distortionary effect of a wage tax on the market for labour-intensive services depends crucially on the substitution elasticity of low and high-skilled labour. If they are perfect substitutes, the market for services is either completely utilized, or does not exist at all, depending on the wage tax rate and the skill premium. In the latter case, a sufficiently lower wage tax can bring about substantial efficiency gains and a service subsidy is not required (provided the initial tax is not too high), resulting in a Pareto-improvement. If both types of labour are not perfectly substitutable, but still quite good substitutes, a service subsidy within a certain range can be Pareto-improving and beneficial to all. For lower degrees of substitutability, whether or not services should be subsidized is a distributional matter: low-skilled benefit, but the utility of high-skilled decreases. The optimal level of the subsidy should then follow from applying a social welfare function.

The results of this paper leave room for further research. One extension would be to include a schooling decision, implying endogenous numbers of low and high-skilled individuals. Another direction is to focus on more specific kinds of services, e.g. child care or old-age care, and allow for a variable amount of services needed, e.g. by treating the fertility rate as an endogenous decision or considering an ageing population. Furthermore, physical capital can be included in the production function of commodities. This will affect the productivity and wages of different skill types in a different way, depending on the degree of substitutability. Because the capital stock is determined by previous investments, which depend on past savings decisions, dynamics will enter the analysis. 
Table 1: Tax rates, skill premium, time use and service subsidies in several OECD countries

\begin{tabular}{l|cc|c|cc|ccc}
\hline \hline & \multicolumn{2}{|c|}{ tax rate } & skill premium & \multicolumn{2}{|c|}{ time use } & \multicolumn{3}{|c}{ subsidy } \\
& $(1)$ & $(2)$ & $(3)$ & $(4)$ & $(5)$ & $(6)$ & $(7)$ & $(8)$ \\
\hline Denmark & 52.7 & 59.9 & 24.7 & n.a. & n.a. & 0.0 & 26.2 & 47.4 \\
France & 39.6 & 42.9 & n.a. & 0.21 & 0.40 & 11.8 & 11.6 & 25.0 \\
Germany & 51.8 & 57.1 & 30.1 & 0.21 & 0.36 & 10.1 & 42.9 & 42.0 \\
Italy & 41.1 & 48.9 & n.a. & 0.14 & 0.46 & 8.3 & n.a. & n.a. \\
Japan & 24.1 & 29.3 & n.a. & 0.12 & 0.38 & n.a. & 20.2 & 17.7 \\
Netherlands & 46.3 & 52.9 & 26.6 & n.a. & n.a. & 10.9 & 40.6 & 78.1 \\
Sweden & 41.4 & 61.1 & 31.9 & 0.21 & 0.31 & 0.0 & 0.0 & 0.0 \\
UK & 35.3 & 40.0 & 35.4 & 0.20 & 0.37 & 8.7 & 9.9 & 79.3 \\
USA & 31.5 & 35.8 & 51.4 & 0.21 & 0.35 & n.a. & 30.1 & 88.3 \\
\hline average & 40.4 & 47.5 & 33.4 & 0.19 & 0.38 & 7.1 & 22.7 & 47.2 \\
\hline \hline
\end{tabular}

(1) Defined as $\frac{1-\tau^{w}}{1+\tau^{c}}$, with $\tau^{w}$ the average wage tax in 2008 (including central and subcentral taxes, and social security contributions) and $\tau^{c}$ the (standard rate of the) VAT, for someone with an average wage (in \%) (source: OECD Tax Database 2009)

(2) Idem, marginal wage tax

(3) Coefficient on workers with a college degree or more relative to high school graduates in a regression of log real annual gross wages on four education categories, mid/late 90s (in \%) (taken from Acemoglu (2003))

(4) Estimate for $(1-x) \zeta$ for men: number of hours per day devoted to unpaid work and care relative to total time devoted to unpaid work, care, leisure and paid work (source: OECD Family Database 2009 (Time Use Survey))

(5) Idem, for women

(6) Estimate for $\theta$, defined as $\frac{\tau^{H}-\tau^{L}}{1+\tau^{H}}$, with $\tau^{H}$ the standard VAT rate and $\tau^{L}$ the reduced VAT rate applied to labour-intensive services such as social services, cleaning, minor repairing etc. (in \%) (source: European Commission (2009))

(7) Estimate for subsidy of child care services, defined as child care benefits, tax benefits and other benefits relative to the child care fee, for a dual earner family with full-time arrangements earning 167\% of the average wage, in 2004 (in \%) (source: OECD Benefits and Wages 2007)

(8) Idem, for a sole-parent family with full-time earnings of $67 \%$ of the average wage 


\section{References}

Acemoglu, D. (2003), 'Cross-country inequality trends', Economic Journal 113, F121-F149.

Bergstrom, T. and Blomquist, S. (1996), 'The political economy of subsidized day care', European Journal of Political Economy 12, 443-457.

Blomquist, S., Christiansen, V. and Micheletto, L. (2009), 'Public provision of private goods and nondistortionary marginal tax rates', American Economic Journal: Economic Policy (forthcoming).

Domeij, D. and Klein, P. (2009), 'Should day care be subsidized?', Working paper January.

Kleven, H. (2004), 'Optimum taxation and the allocation of time', Journal of Public Economics 88, 545-557.

Kleven, H., Richter, W. and Sørensen, P. (2000), 'Optimal taxation with household production', Oxford Economic Papers 52, 584-594.

Lindbeck, A. (1982), 'Tax effects versus budget effects on labor supply', Economic Inquiry 20(4), 473-489.

Lundholm, M. and Ohlsson, H. (1998), 'Wages, taxation and publicly provided day care', Journal of Population Economics 11, 185-204.

Mumford, K. (2008), 'The efficiency cost of child tax benefits', Krannert Working Paper $\mathbf{1 2 2 0 .}$

Rosen, S. (1995), 'Public employment, taxes and the welfare state in Sweden', NBER Working Paper (5003).

Sandmo, A. (1990), 'Tax distortions and household production', Oxford Economic Papers 42, 78-90. 
Figure 2: Effects of a service subsidy with $\tau=40 \%$, linear production $(\mu=1)$

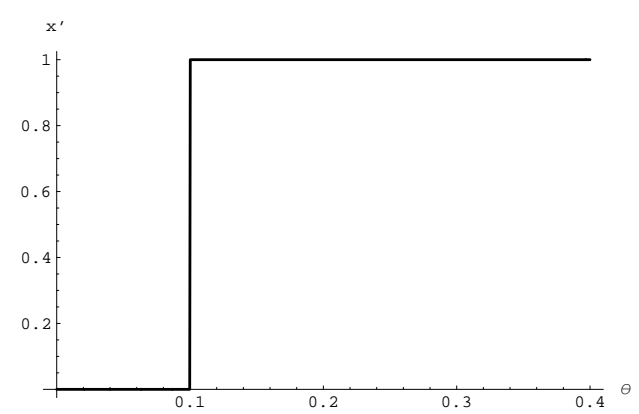

(a) Services purchased

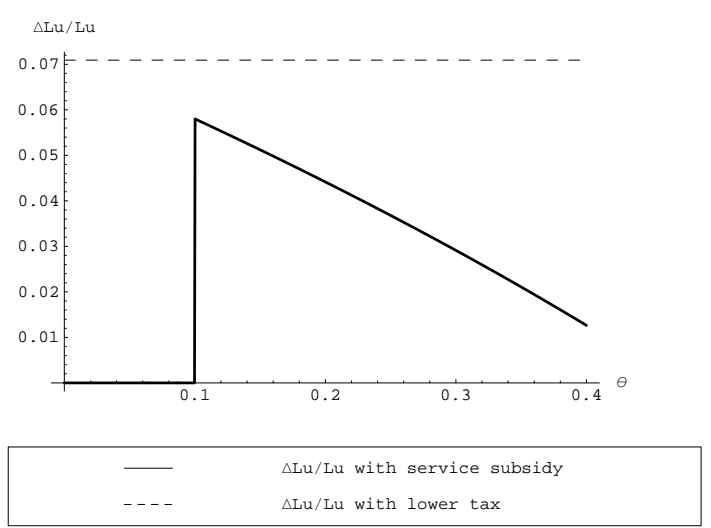

(c) Relative change in low-skilled labour supply
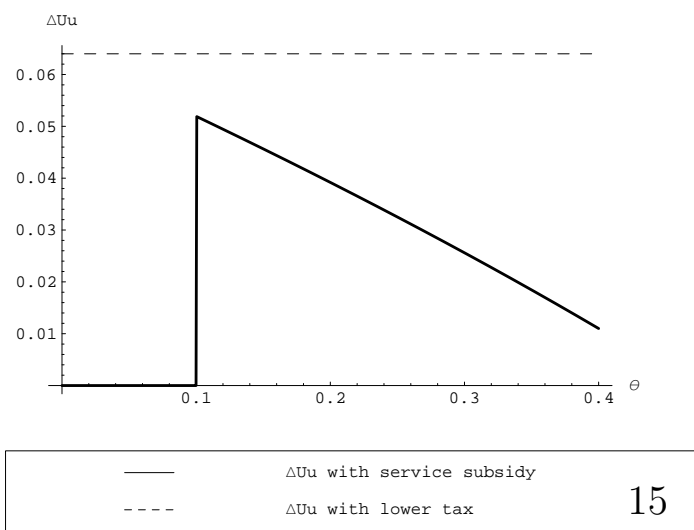

(e) Change in utility low-skilled

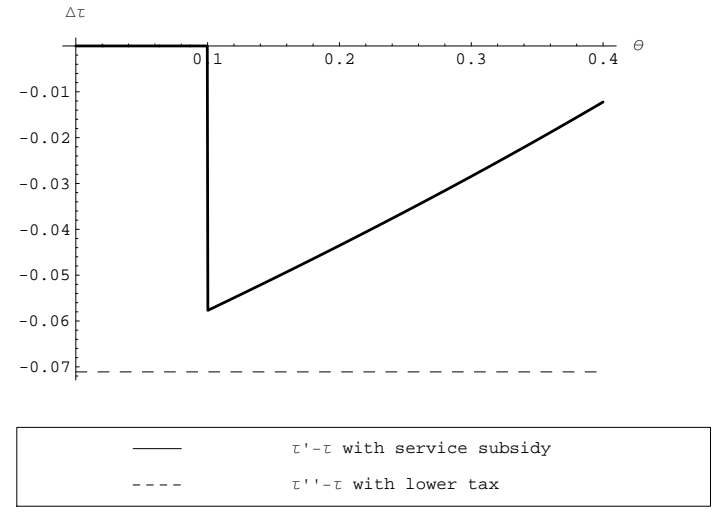

(b) Change in tax rate

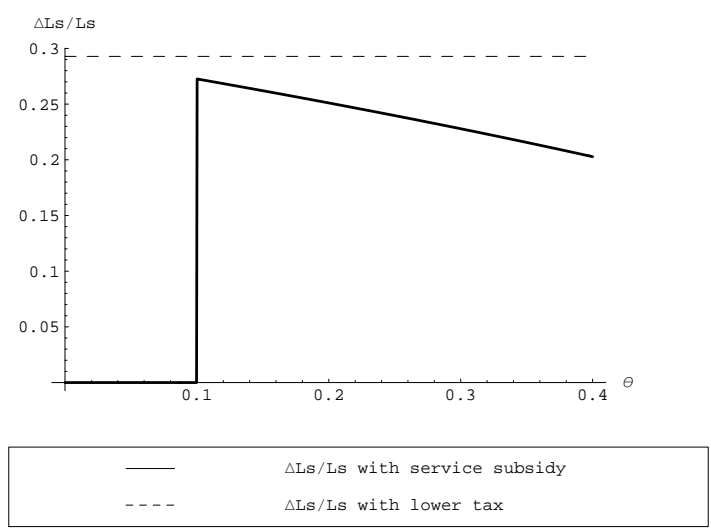

(d) Relative change in high-skilled labour supply

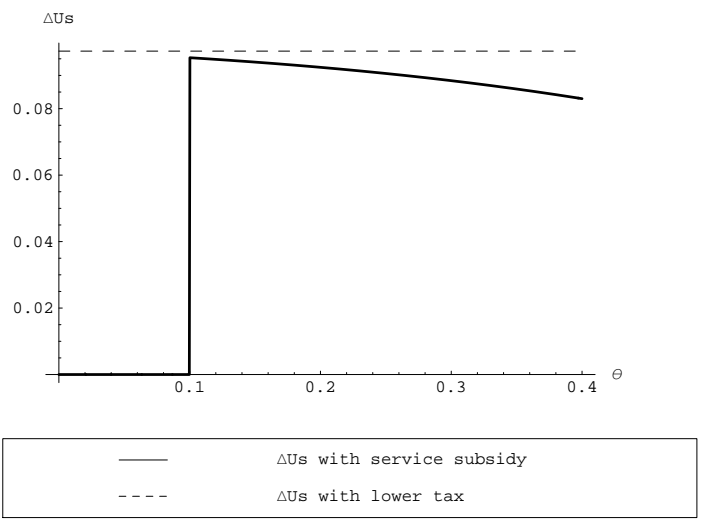

(f) Change in utility high-skilled 
Figure 3: Effects of a service subsidy with $\tau=40 \%$, Cobb-Douglas production $(\mu=0)$

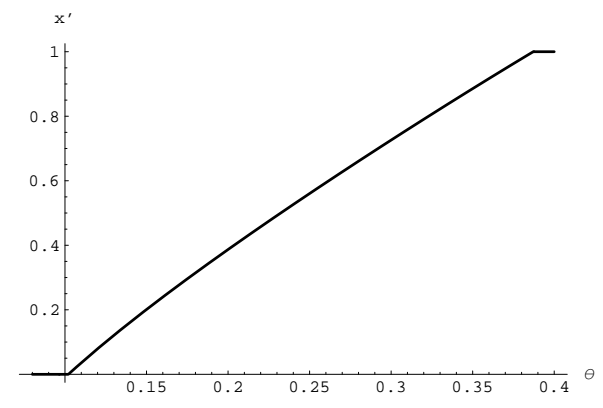

(a) Services purchased

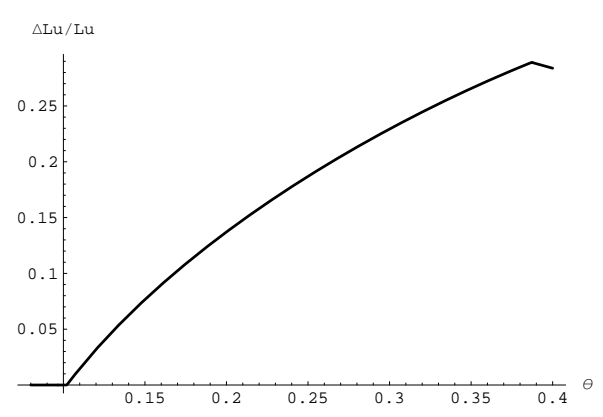

(c) Relative change in low-skilled labour supply

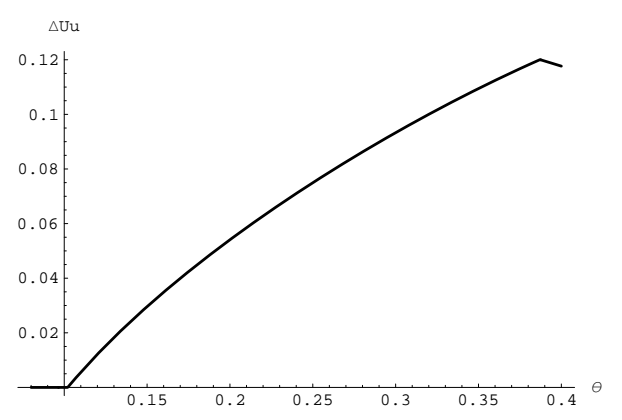

(e) Change in utility low-skilled

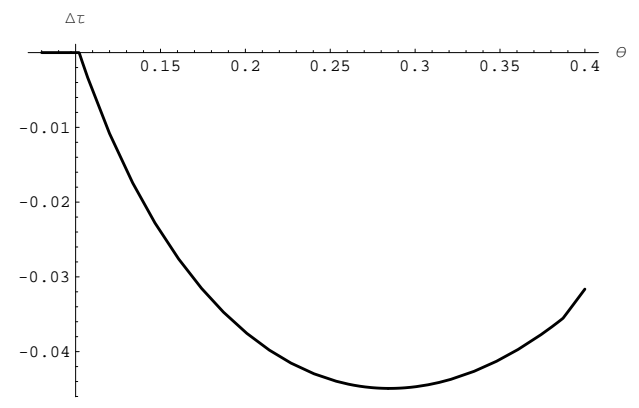

(b) Change in tax rate



(d) Relative change in high-skilled labour supply

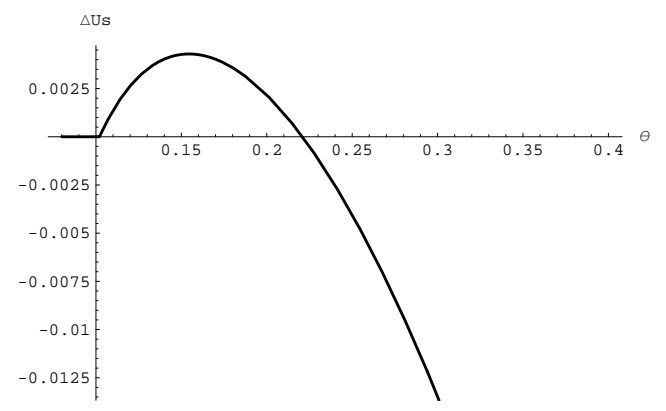

(f) Change in utility high-skilled 
Figure 4: Effects of a service subsidy with $\tau=40 \%$, high and low-skilled labour complements $(\mu=-10)$

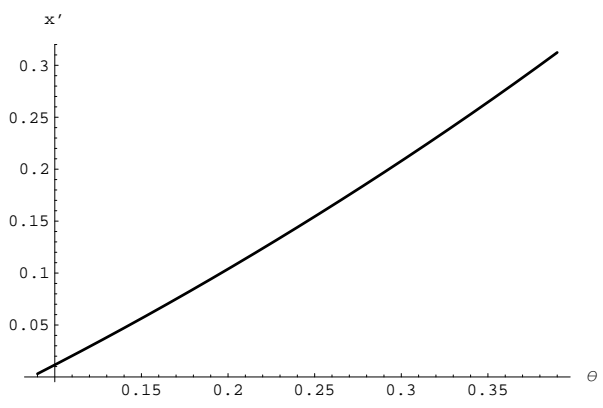

(a) Services purchased

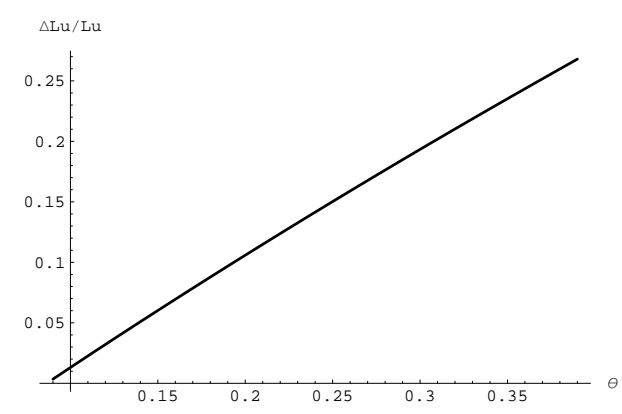

(c) Relative change in low-skilled labour supply

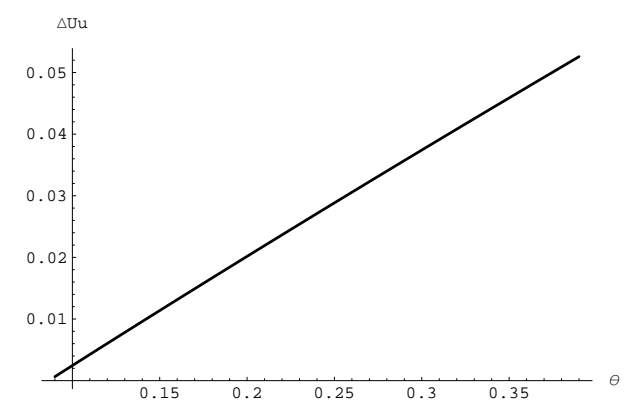

(e) Change in utility low-skilled

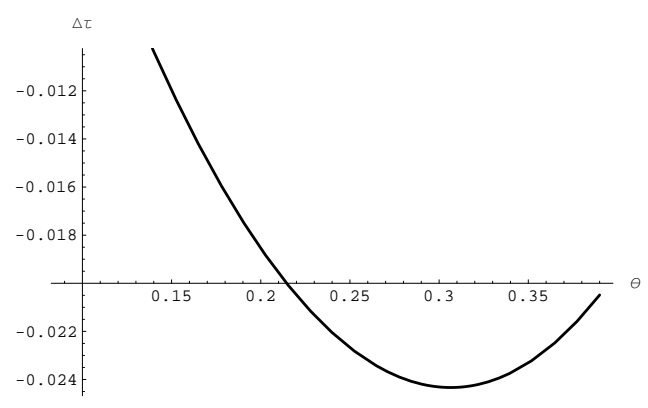

(b) Change in tax rate

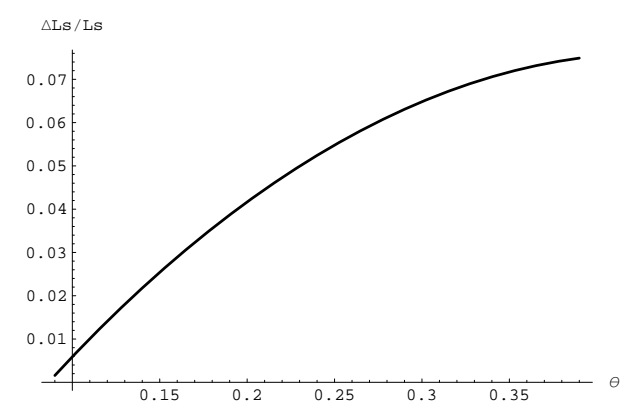

(d) Relative change in high-skilled labour supply

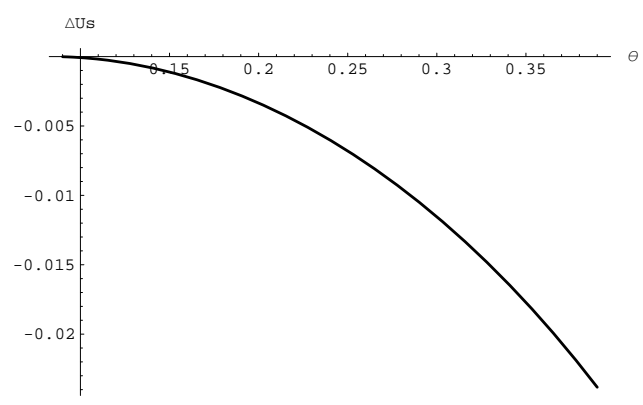

(f) Change in utility high-skilled 